\title{
Motivational Factors Affecting the Integration of Information and Communication Technology (ICT) in Education by Faculty Members: A Developing Country Perspective
}

\author{
Al-Mothana M. Gasaymeh ${ }^{1,}{ }^{*}$, Hasan A. Al-hasanat ${ }^{1}$, Osama M. Kraishan ${ }^{1}$ \& Khaled A. \\ Abutayeh $^{1}$ \\ ${ }^{1}$ Curriculum and Instruction Department, Al-Hussein Bin Talal University, Ma'an, Jordan \\ *Correspondence: Curriculum and Instruction Department, Al-Hussein Bin Talal University, \\ Ma'an, Jordan. E-mail: gasaymeh@gmail.com
}

Received: July 10, 2017 Accepted: August 2, 2017 Published: September 27, 2017

doi:10.5296/ije.v9i3.11667 URL: https://doi.org/10.5296/ije.v9i3.11667

\begin{abstract}
The purpose of this study was to examine motivational factors affecting the integration of Information and Communication Technology (ICT) in the educational practices of faculty members at a university in Jordan. A quantitative approach was used in which 35 participants completed a questionnaire. They were faculty members who were teaching in the first semester of the 2016-2017 academic years. The participants reported limited use of ICT for educational purposes. The most significant motivational factors they reported were internal and personal ones related to the direct benefits of ICT in terms of enhancing their teaching practice, enhancing students' learning, and improving their job satisfaction. External factors including physical and moral motivational factors, as well as university support and encouragement, had a moderate influence on the participants' use of ICT for educational purposes. Recommendations are presented based on the findings.
\end{abstract}

Keywords: faculty members, internal and external motivational factors, ICT integration, education, developing country. 


\section{Introduction}

There has been increasing interest in integrating Information and Communication Technology (ICT) into higher education processes. This interest is driven by the anticipated benefits. These benefits can be categorized into four interrelated types: benefits for students, benefits for faculty members, benefits for the university, and benefits for the country. Examples of benefits for students include enhancing their learning, increasing their motivation, facilitating communication and collaboration, making their study flexible, and increasing their access to educational resources and programs. Examples of benefits for faculty members include facilitating the creation of digital educational materials, streamlining administrative tasks, and saving time. Examples of benefits for universities include recruiting more students, saving money, streamlining administrative tasks, and enhancing university rankings. Examples of benefits for countries include increasing access to education, creating lifelong learners, and training highly qualified workers who can compete in global economy.

In Jordan, there has been increasing interest in integrating ICT into higher education for administrative and educational purposes. This interest is evident in the policies and regulations in higher education institutions that encourage faculty members to integrate ICT into their educational and administrative practices. For instance, each university in Jordan has a computer center that is responsible for supporting the university's teaching process by providing faculty members with electronic programs and equipment. In addition, each center is responsible for providing and enhancing the internet services and computer services for faculty members and students. It is responsible for internet and mobile phone registration systems, video conferencing, internet-based and computer-based tests, electronic support and maintenance, and portal services. In addition, faculty members in Jordanian university are required to have International Computer Driving Licence (ICDL) in order to promote the integration of ICT in their educational practice.

Present-day students are characterized as "Digital Natives" or the "Net Generation" (Prensky, 2001; Margaryan, Littlejohn, \& Vojt, 2011). This refers to the fact that these students have high digital competency, they are heavy users of a range of technologies, and they have developed new cognitive capacities and learning styles as a result of their experience with these technologies (Prensky, 2001). In Jordan, university students own different ICTs such as smartphones and laptops (Al-Shboul, Al-Saideh, \& Al-Labadi, 2017) and they have easy access to the internet through their phones. They are heavy users of popular ICTs such as social networking sites (SNSs) and smartphone apps and services (Bsharah, Gasaymeh, \& Abdelrahman, 2014; Alimat \& Altah 2014). They have positive attitudes and perceptions of the use of different types of ICT in their informal and informal education (Gasaymeh, \& Aldalalah, 2013; Gasaymeh, \& Qablan, 2013; Al-Shboul, Al-Saideh, \& Al-Labadi, 2017; Gasaymeh, Al-Tawel, Al-Moghrabi, \& Al-Ghonmein, 2017). However, students' level of use of ICT in their learning depends on the extent to which faculty members enable students to use ICT for educational and administrative tasks.

The current study examined motivational factors affecting the integration of ICT into educational practice by faculty members. It did so with an awareness of: the benefits of the 
integration of ICT into higher education, the government's interest in integrating ICT into Jordanian higher education, students' dependence on and heavy use of different types of ICT, and the integral roles of faculty members in the integration of ICT in the institutions of higher education.

\section{Theoretical Framework}

Motivations can be defined as the external and internal factors and influences that encourage individuals to increase their production, achieve outstanding performance, and to change their behaviors and attitudes. As such, they lead to increases in employees' satisfaction and loyalty to the organizations where they work, which, in turn leads to improved performance (Abu-Al-Kishk, 2006). On the other hand, motivation could be defined as the power which impels the individual to improve their performance. In some cases the managements of organizations have control over this power, and direct it towards increasing the effort that employees expend at work. This is a process that can be achieved by linking the external factors which comprise the work environment and the internal factors which affect the individual, including their physiology, culture, cognition, skill levels, and job satisfaction (Helal, 2009).

Workers' motivations can be influenced by certain objectives of the organization's management. Examples of these objectives include production improvement, raising the morale of the workers, retention of outstanding workers, rewarding outstanding performance, encouraging creativity and innovation, and encouraging workers who demonstrate medium-level performance to progress to higher levels (Al-Kharabsheh, 1995). Motivating individuals is directly related to incentives system. Fisher (2003) focused on the relationship between the incentives system and performance excellence; there is no job excellence without offering an incentive. Consequently, the effect of an incentive depends on acknowledging good performance and rewarding the individual. According to Abdul-Aziz (2008) the importance of incentives is related to achieving many benefits for the individual and the organization, such as, satisfying workers' needs and desires; increasing their loyalty and sense of belonging to the organization; developing a spirit of cooperation among them; encouraging improvements in efficiency; attracting skilled workers to the organization and improving the image of the organization in the eyes of the community.

\subsection{Types of Incentives}

Zweilef (2000) argued that there are two types of incentives: material incentives and moral incentives. The former include wages, annual allowances, rewards, sharing the profits, and health insurance. The latter include promotion, appreciation of the workers' efforts, and ensuring a stable work environment. There are two types of approaches that can be used to influence behavior: incentives and disincentives. Incentives encourage the development of creativity and innovation, and they include material and moral incentives. Disincentives are punishments. They are used to discourage behaviors which are considered undesirable. They may lead to changes in an employee's behavior, and, subsequently, improve his/her 
performance and conduct. According Rabab'ah (2003) incentives can be:

- individual incentives which are offered to individuals for performing a certain job, or achieving the targeted objective in less than the scheduled time

- group incentives which are offered to groups of workers to promote the solidarity of workers in their efforts to achieve objectives, and increase efficiency and productivity

- distinction incentives which attempt to ensure continuous improvement and development by encouraging workers based on differences in their individual performances.

\subsection{Internal and External Motivations}

Motivation is a crucial determinant of workers' eagerness to work and of the organization's ability to achieve its objectives. The motivation process itself is affected by internal and external factors that encourage individuals to improve their performance and to achieve favorable behaviors (Hamdan \& Al-Saket, 2011).

Internal motivations are those related to the work itself and include individuals' feelings of responsibility toward their work. They allow the individual to use and employ his/her skills and abilities. They could be linked to autonomy at work, the use of different and positive skills, and obtaining feedback concerning the work itself (Ashour, 1996). Internal motivations vary from one job to another; they have a major influence on performance and job satisfaction.

External motivations are not related to the work itself; they relate to other sources in the organization. These external motivational factors include material incentives, professional colleagues' appreciation, and promotions and remuneration. In addition, external motivational factors include wages and other financial rewards; and promotion and appreciation, from both supervisors and colleagues (Hashem, 1975).

To summarize, internal motivational factors are those linked to the occupation itself, and external motivational factors are related to other sources in the organization, including work colleagues, and supervisors. For management, providing and controlling internal incentives is more difficult than providing external incentives. Internal and external incentives interact with each other in a complex manner, through their influence on the individual's conduct and performance. In the current study internal and external motivations for faculty members' use of ICT in their educational process were examined. The next section discusses research that has investigated faculty members' use of ICT in their educational practice and the factors that might encourage such use.

\section{Literature Review}

Faculty members' use of ICT in their educational practice has been examined in different ways in different countries. In Nigeria, Asiyai (2014) examined faculty members' use of ICT in their teaching. Asiyai used a survey in which 560 students and lecturers completed a questionnaire. The results showed that the faculty members believed that there are several 
benefits of using ICT in higher education: enhancing the quality of teaching, matching learning styles; and enhancing collaborative networking and research. However, the participants believed that the main barriers to the effective use of ICT in higher education settings were a lack of adequate governmental ICT policies, a lack of funds, and a lack of ICT literacy among students and faculty members.

In Iran, Salehi, Abdolahi, Tabaghdehi, and Mastari, (2014) investigated the factors that influenced faculty members' use of ICT in a university. Seventy seven faculty members completed a questionnaire. The results indicated that the factors that influenced the use of ICT were related to cost and capital (e.g., the budget for using ICT); educational (e.g., access to technology); technical and structural (e.g., the availability of sufficient facilities); and skills (e.g., knowledge about using ICT in teaching).

Different studies have employed different models of adoption to examine faculty members' use of specific types of ICT and the factors that influence the use of specific types of ICT. In the US, Fathema, Shannon, and Ross (2015) used the extended version of the Technology Acceptance Model (TAM) to examine the factors that influenced faculty members' use of a Learning Management System (LMS). A cross-sectional design was used in which 560 faculty members from two universities completed a questionnaire. The results showed that system quality; perceived self-efficacy, perceived ease of use, perceived usefulness, and attitude toward technology directly or indirectly influenced faculty members' use of the LMS. In another study in the US, Gautreau, (2011) examined the factors that influenced faculty members' use of an LMS. A total of 42 faculty members completed a questionnaire that consisted of 30 items that were grouped into seven potential factors that could motivate faculty members to use an LMS in their teaching. The findings showed that the participants' ranking of these factors was (1) salary, (2) responsibility, (3) achievement, (4) advancement, (5) company policy and administration, (6) the work itself, and (7) recognition.

In Canada, Dougherty (2015) used modified decomposed theory of planned behavior (DTPB) to examine the factors that affected faculty members' adoption of ICT in their educational practice. A mixed research method was used in which 273 faculty members completed a questionnaire and 14 participants were interviewed. The results showed that the main factors that encouraged faculty members to employ ICT in their educational practice include the usefulness of the technologies, administrative pressures to increase the use of ICT, the availability of time to engage in the process of integrating ICT in their educational practice, perceived usefulness for improving students' learning, training in how to use ICT in the educational process, institutional support, institutional norms, compatibility, and rewards.

In Norway, Schulz, Isabwe, and Reichert (2015) examined faculty members' perceptions of the motivational factors for using ICT tools in higher education. A questionnaire was used to collect data from 45 participants. The results indicated that the factors motivating participants to use ICT tools in their teaching could be categorized into three groups: human factors (e.g., faculty members' skills, attitudes and opinions towards the tools); internal factors (e.g., faculty members' satisfaction, level of interest, joy and entertainment); and factors related to user requirements for ICT (e.g., usability, level of interactivity, adaptability, and meeting 
learning requirements).

In Jordan, Al-Omari (2015) investigated faculty members' reluctance to use an e-learning system in a university. Two hundred faculty members were randomly selected to complete a questionnaire. The results indicated that the main disincentives were a lack of efficient infrastructure, students' lack of skills, and workloads. In another similar study that was conducted in another university in Jordan, Al-Hawamdeh (2011) examined the obstacles that faculty members faced in their efforts to employ e-learning tools in their teaching practice. A descriptive approach was used, in which 96 faculty members completed a questionnaire. The results showed that there were three main types of obstacles: administrative and material obstacles (e.g., lack of appropriate infrastructure and tools); obstacles related to the students and faculty members (e.g., lack of knowledge and skills); and obstacles related to e-learning (e.g., lack of e-learning applications in the Arabic language). In an earlier study, Gasaymeh (2009) examined Jordanian faculty members' attitudes toward internet-based distance education and the factors that might influence their attitudes towards it. The results showed that the faculty members had moderately positive attitudes toward internet-based distance education. Gasaymeh found that the faculty members' attitudes toward internet-based distance education can be predicted by: computer and internet access, time commitments, computer and internet skills, perceived value, and institutional support.

Stakeholders in institutions of higher education can benefit from the use of ICT for educational and administrative purposes. Students nowadays are familiar with the use of different types of ICT. In developing countries there has been increasing interest in integrating ICT into higher education systems. However, faculty members play an integral role in the ICT integration process and in enabling students to use ICT for educational and administrative tasks. Internal and external motivations will influence the perceptions and behaviors of faculty members regarding the integration of ICT in their teaching and administrative practices. Previous studies have identified different factors that influence faculty members' adoption of ICT for educational purposes. The types of factors and the intensity of their effects on faculty members' motivations vary from one study to another.

\section{Purpose of the Study}

A limited number of studies have examined the motivational factors for ICT use among faculty members in Jordan. Policy makers and educational practitioners need to understanding faculty members' perceptions of the motivational factors affecting their use of ICT so that they know how to encourage faculty members to use ICT. The purpose of the study was to examine the motivational factors affecting faculty members' integration of ICT into their educational practice.

\section{Research Methods}

A quantitative approach was used in this study. A cross-sectional survey design was used in 
which the participants completed a questionnaire. The questionnaires collect data on faculty members' perceptions of the motivational factors which encouraged them to integrate ICT into their educational practice.

\subsection{Participants}

The participants were 35 faculty members who were teaching in a university in Jordan in the first semester of the 2016/2017 academic year. A summary of participants' demographic characteristics and their use of ICT are presented in Table 1.

Table 1. Descriptive Summary of Participants' Characteristics

\begin{tabular}{llcc}
\hline & Category & Frequency & Percent \\
\hline Gender & Male & 26 & 74.3 \\
\multirow{3}{*}{ Age } & Female & 7 & 20.0 \\
& less than 30 & 1 & 2.9 \\
\multirow{4}{*}{ Major } & $31-45$ & 21 & 60.0 \\
& $45+$ & 12 & 34.3 \\
& Education & 11 & 31.4 \\
& Engineering and Computer Science & 12 & 34.3 \\
& Arts and Literatures & 6 & 17.1 \\
Rank & Science & 4 & 11.4 \\
& Business Management & 1 & 2.9 \\
& Lecturer & 12 & 34.3 \\
& Assistant Professor & 10 & 28.6 \\
\multirow{3}{*}{ Use of ICT } & Associate Professor & 9 & 25.7 \\
& Full Professor & 3 & 8.6 \\
& High & 4 & 11.4 \\
& Medium & 4 & 11.4 \\
& Low & 27 & 77.1 \\
\hline
\end{tabular}

About three-quarters of the participants $(74.3 \%, n=26)$ were male and $20 \%(n=7)$ were female while two participants did not provide response to gender question. About two-thirds of the participants $(60 \%, n=21)$ were between the ages of 31 and 45 and about one third of the participants $(34.3 \%, n=12)$ were older than 45 . Only one participant was younger than 30 . The largest cohorts of participants were from the education department $(31.4 \%, n=11)$ and the engineering and computer science departments $(34.3 \%, n=12)$. Seventeen per cent $(n=6)$ were from the arts and literature department, $11.4 \%(n=4)$ were from the science department, and one participant was from the business management department. Twelve participants $(34.3 \%)$ were lecturers, ten $(28.6 \%)$ were assistant professors and nine $(25.7 \%)$ were associate professors. Only $8.6 \%(n=3)$ were full professors. The great majority of the participants $(77.1 \%, n=27)$ reported low levels of use of ICT in their educational practice. 


\section{$\triangle$ Macrothink}

Only $11.4 \%(n=4)$ reported medium levels of use and $11.4 \%(n=4)$ reported a high level of use.

\subsection{Instrument}

The questionnaire instrument used in the study was developed based on the literature (e.g., Gasaymeh, 2009; Gautreau, 2011; Dougherty, 2015). The questionnaire instrument had two sections. The first section consisted of questions about participants' demographic characteristics and their use of ICT. The second section consisted of a set of factors that potentially motivated faculty members to use of ICT in their educational practice. A five-point Likert scale was used in the in the second section. The proposed levels of the mean scores of the five-point Likert items were presented in Table 2.

Table 2. The Levels of the Mean Scores

\begin{tabular}{ll}
\hline Level & Mean scores \\
\hline Very low & 0.0 to 1.49 \\
Low & 1.5 to 2.49 \\
Moderate & 2.5 to 3.49 \\
High & 3.5 to 4.49 \\
Very high & 4.5 to 5 \\
\hline
\end{tabular}

\subsection{Procedure}

The data was collected in the first semester of the 2016/2017 academic year. The participants were faculty members who were teaching in that semester in a university in Jordan. In order to collect the data, the authors distributed paper copies of the questionnaire in the different departments in the university. Each department's chairperson was asked to hand the questionnaires to the department's faculty members, and to collect them when they had been completed. After two weeks, the authors received the completed questionnaires from the chairpersons.

\subsection{Data Analysis}

Descriptive analysis was used to analyze the questionnaire data. Frequency distributions were calculated for participants' demographic data and their use of ICT. Descriptive statistics, including ranks, means and standard deviations, were used to describe faculty members' perceptions of the factors that would influence their use of ICT in their educational practice.

\section{Results and Discussion}

The questionnaire collected data regarding faculty members' perceptions of the motivational factors which encouraged them to integrate ICT into their educational practice. The ranks, means and the standard deviations for the faculty members' responses to each item are presented in Table 3. 


\section{$\triangle$ Macrothink}

Table 3. The ranked orders, the means, and standard deviations of motivational factors

\begin{tabular}{|c|c|c|c|}
\hline Rank & Factors & $\mathbf{M}$ & SD \\
\hline 1. & Opportunity for scholarly pursuit & 3.94 & .97 \\
\hline 2. & Opportunity to expand program offerings & 3.91 & 1.01 \\
\hline 3. & Opportunity to improve my teaching & 3.91 & 1.09 \\
\hline 4. & Ability to reach new students that cannot attend classes in campus & 3.89 & 1.18 \\
\hline 5. & Greater course flexibility for students & 3.80 & .93 \\
\hline 6. & Personal motivation to use technology & 3.71 & 1.05 \\
\hline 7. & Opportunity to use personal research as a teaching tool & 3.69 & 1.13 \\
\hline 8. & Career exploration & 3.69 & 1.16 \\
\hline 9. & Overall job satisfaction & 3.63 & 1.14 \\
\hline 10. & Opportunity to develop new ideas & 3.60 & 1.14 \\
\hline 11. & Reduce training load & 3.46 & 1.01 \\
\hline 12. & Job security & 3.23 & 1.14 \\
\hline 13. & Credit toward promotion and tenure & 3.23 & 1.31 \\
\hline 14. & Expectations by university that faculty would use ICT & 3.17 & 1.04 \\
\hline 15. & Support and encouragement from university administrators & 3.14 & 1.17 \\
\hline 16. & Visibility for jobs at other institutions / organizations & 3.11 & 1.18 \\
\hline 17. & Training provided by the university & 3.03 & 1.27 \\
\hline 18. & Increase in salary & 3.00 & 1.33 \\
\hline 19. & Release time & 3.00 & 1.11 \\
\hline 20. & Recognitions and awards & 3.00 & 1.19 \\
\hline 21. & Monetary support for participation (stipend, overload) & 2.97 & 1.15 \\
\hline 22. & Technical support provided by the university & 2.97 & 1.15 \\
\hline 23. & Grants for materials / expenses & 2.91 & 1.17 \\
\hline 24. & Requirement by department & 2.89 & 1.11 \\
\hline 25. & Support and encouragement from department colleagues & 2.80 & 1.08 \\
\hline 26. & Payments on copyrighted material & 2.80 & 1.11 \\
\hline 27. & Working conditions (hours, location) & 2.74 & 1.04 \\
\hline 28. & Support or encouragement from Dean or chair & 2.60 & 1.12 \\
\hline 29. & Professional prestige and status & 2.54 & 1.07 \\
\hline 30. & Graduate training received & 2.29 & 1.07 \\
\hline
\end{tabular}

Note. Light blue background $=$ high mean scores, Orange background $=$ moderate mean scores, Light green background $=$ low mean scores.

Table 2 shows that the means of faculty members' responses to the motivational factors ranged from low $(M=2.29, S D=1.07)$ to high $(M=3.94, S D=.97)$. The faculty members believed that the most important factor that would encourage them to use ICT was "Opportunity for scholarly pursuit" and they believed that the least important motivational factor was "Graduate training received". The majority of the participants agreed that the most important factors (i.e., the ones that had high mean scores) that would motivate them to 
employ ICT in their education were internal ones. Some of them were related to the work itself. These included: providing diverse teaching methods and educational programs, improving teaching methods, reaching more students, helping students to have flexible access to educational materials and programs, using research results in their teaching, and developing new educational ideas. Other important factors were related to personal motivation for using ICT, opportunities advance their careers, and feeling satisfied with their jobs. These findings align with the findings of other studies. For instance, Asiyai, (2014) found that faculty members and students believed that the integration of ICT in their educational practice had several benefits including: enhancing the quality of their teaching, matching learning styles, and enhancing collaborative networking and research. Salehi, et al. (2014) reported that "educational benefits" was one of four factors that encouraged faculty members to integrate ICT into their educational practice. Dougherty (2015) found that the usefulness of ICT was the main factor motivating faculty members to use ICT in their educational practice. However, the findings are at odds with the findings of some other studies. For instance, Gautreau (2011) found that the most important factors that would motivate faculty members to use LMS technology were financial incentives. The emphasis that the participants placed on the benefits of ICT on teaching practice and student learning may have been due to cultural factors. Arab culture is collectivist rather than individualistic (Ameen, \& Willis, 2015 (Ameen, \& Willis, 2015). Therefore, faculty members emphasize the benefits for teaching practice and for students above their individual needs or desires (e.g., material and moral incentives). The findings suggest that for the faculty members the most important motives for using ICT were related to the direct benefits for their teaching practice, for students' learning, and for career development.

Most of the external motivations related to monetary rewards and saving time had a moderate influence on faculty members' use of ICT in their teaching. The faculty members moderately agreed that some factors would influence their use of ICT in their education, these factors include: increases in salary, credit toward promotion and tenure, release time, recognitions and awards, monetary support for participation, grants for materials and expenses, royalties on copyrighted material, visibility for jobs at other institutions, greater job security, improved working conditions (hours, location), reduced training loads, professional prestige, and higher status. The findings aligned with the findings of other studies. For instance, Gautreau (2011) found that faculty members believed that financial incentives were the most important motivational factors for using LMS. Dougherty (2015) found that faculty members believed that rewards and recognition would moderately influence their use of ICT. Such findings can be explained by the importance of the time, finances, and moral related incentives and the economic characteristics of Jordan. According to Zweilef (2000) material and moral incentives are important motivational factors. Jordan suffers from economic challenges; and this means that incomes are low. Therefore, the faculty members would be influenced by the offer of material incentives to integrate ICT into their educational practices. The findings suggest that faculty members could be encouraged to use ICT through time-related incentives and financial incentives.

Incentives provided by the university could have a moderate influence on faculty members' 
integration of ICT in their educational practice. There was a moderate level of agreement among faculty members that their use of ICT would be influenced by: the university's expectations, support and encouragement from university administrators, training and technical support provided by the university, requirements by university departments, support and encouragement from department colleagues, and support or encouragement from deans or chairs. These findings align with the findings of other studies. Asiyai (2014) found that a lack of governmental and institutional support would negatively influence faculty members' use of ICT in their educational practice. Salehi et al. (2014) found that the availability of adequate budgets and suitable technical and structural resources would encourage faculty members to use ICT. Dougherty (2015) found that the some of the main factors that would encourage faculty members to employ ICT in their educational practice included administrative pressure to increase the use of ICT, institutional support, and institutional norms. In Jordan, similar studies have focused on the importance of institutional support to motivate faculty members to use ICT in their educational practice (Gasaymeh, 2009; Al-Hawamdeh, 2011; Al-Omari, 2015). As expected, these studies found that faculty members would respond to their institutional requirements and encouragement regarding the implementation of ICT. The findings suggest that faculty members can be motivated to use ICT in their educational practice by the institutional requirements and support.

Finally the results showed that "graduate training received" scored the lowest mean score among the factors that would motivate faculty members to use ICT in their educational practice. The faculty members believed that several other factors were more important than training in the use of ICT, such as the anticipated benefits of ICT on their jobs and students' learning, the material and moral incentives to use ICT, and institutional requirements and support for the use of ICT. However, the faculty members believed that as a motivator for encouraging them to use ICT, training provided by the university was more important than training in their graduate studies. A similar finding was reported by Dougherty (2015) who found that training in how to use ICT in the educational process was a motivational factor for faculty members in their use of ICT. The findings suggest that "timely training" would motivate faculty members to use ICT in their educational practice.

\section{Conclusion and Recommendations, and Limitations}

An understanding of faculty members' views on which motivational factors would encourage them to integrate ICT into their educational practice is important for the successful introduction of ICT in higher education. Incentives are important for enhancing individual performances and achievements. They are important for both individuals and organizations (Fisher, 2003; Abdul-Aziz, 2008). The integration of ICT into higher education has benefits for all stakeholders. In developing countries there has been increasing interest in integrating ICT into higher education. This interest is driven by the availability and affordability of several types of digital technology in the hands of the university students and in universities. University students are heavy users of popular ICTs for personal and social purposes. However, the integration of ICT into higher education, and students' use of ICT for 
educational purposes, depends on faculty members' practices.

The participants in this study reported limited use of ICT for educational purposes. However, they reported that several motivational factors would encourage them to integrate ICT into their educational practice. The most significant factors were internal and personal ones related to the direct benefits of the ICT for enhancing their teaching practice, enhancing students' learning, and improving their job satisfaction. Material and moral incentives, as well as university support and encouragement, have a moderate influence on faculty members' use of ICT for educational purposes. The findings suggest that the faculty members could be motivated to use ICT in their educational practice if the university supported them to integrate ICT in ways that enhanced their teaching and benefited their students. In addition, faculty members could be motivated to use ICT in their educational practice by offering them time-related and financial incentives. The university could play an integral role in motivating faculty members to implement ICT in their educational practice by: requiring the use of ICT, encouraging the use of ICT, and providing "timely training and support" related to the use of ICT.

Faculty members' instructional practices are driven by their motivations. Therefore, it is important for institutions of higher education to understand what measures would encourage faculty members to integrate ICT in their educational practice. Based on the findings, the institutions of higher education should increase their faculty members' awareness and knowledge of the anticipated benefits of the use of ICT in their educational practice in term of enhancing their teaching practice and career and improving their students' learning. In order to enhance faculty members' awareness and knowledge of the anticipated benefits of the use of ICT, presentations, seminars, regular meetings with faculty members who had experience with the use of ICT in education can be conducted.

The institutions of higher education should encourage faculty members through establishing financial, moral, incentive system to promote faculty members' integration of ICT in their educational practice. Such system should include different types of incentives such as monetary, time related, job security related, working conditions related, and recognition incentives. The incentive system should include continuous process of identifying and meeting the motivational factors of faculty members. Institutions of higher education should continually support faculty members in their integration of ICT in their educational practice through requiring them to use ICT, encouraging them to use ICT, and providing "timely training and support" related to the use of ICT in their educational practice. Faculty members should be constantly encouraged and supported to make the integration of ICT part of their permanent educational practice. It is not enough to only encourage them to try to integrate ICT into their educational practice. The integration of ICT should be inherent in the higher education institutions' mission, vision, and philosophy. This is needed to motivate faculty members' integration of ICT into their educational practice.

The study has some limitations related to the participants, methodology, and the ICT it examined. The study had a small number of participants and they all came from one university in Jordan. This limits the generalizability of the findings. Future research should 
include more participants from more than one university. Besides examining faculty members' perceptions of motivational factors for the use of ICT, future research should examine university students' and administrators' perceptions. This study used a quantitative approach in which self-reported data was collected using a questionnaire. Future research should involve triangulation technique in order to validate the collected data. The current study discussed the faculty members' adoption of ICT in general. Future research should focus on faculty members' perceptions of the motivational factors, obstacles, and needs related to specific types of ICT in order to provide specific recommendations.

\section{References}

Abdul-Aziz, A. (2008). Distinguished Management of the Human Resources, Borders' Distinction. Modern Bookshop, Al-Mansoura, Egypt.

Abu-Al-Kishik, M. (2006). Contemporary School Management. Dar Jareer for Publishing, Amman-Jordan.

Al-Hawamdeh, M. (2011). Obstacles of e-learning integration from the point of views of faculty members at Al-Balqa Applied University. Journal of Damascus University, Retrieved from http://www.damascusuniversity.edu.sy/mag/edu/images/stories/803-831.pdf

Alimat, H., \& Altah, Z (2014). The extent of the use of social interaction media on the Internet by Al-Bayt University students. Al - Manara Journal for Research and Studies 20(1), 55-73.

Al-Kharabsheh, O. (1995). Stimulations and Their Applications, When and Why Managers Decide Award Incentives to the Employees? Union and Management Magazine, Amman, $17(63)$.

Al-Omari, M. (2015). Reasons for the Reluctance of Faculty Members at Yarmouk University in the Use of E-learning System on the University's Web Site from Their Point of View. The Jordanian Journal of Educational Sciences, 11(4), 417-426

Al-Shboul, M., Al-Saideh, M., \& Al-Labadi, N. (2017). Learners' perspectives of using ICT in higher education institutions in Jordan. Instructional Technology, 14(3), 27-86.

Ameen, N., \& Willis, R. (2015). The effect of cultural values on technology adoption in the Arab countries. International Journal of Information Systems, 2 Retrieved from https://www.researchgate.net/profile/Nisreen_Ameen2/publication/290130692_THE_EF FECT_OF_CULTURAL_VALUES_ON_TECHNOLOGY_ADOPTION_IN_THE_AR AB_COUNTRIES/links/5694f6ac08ae3ad8e33d39bf/THE-EFFECT-OF-CULTURALVALUES-ON-TECHNOLOGY-ADOPTION-IN-THE-ARAB-COUNTRIES.pdf

Ashour, A. (1996). Human Conduct in the Organizations. Dar Al-Ma'rifa Al-Jamiah, Cairo.

Asiyai, R. I. (2014). Assessment of Information and Communication Technology Integration 
in Teaching and Learning in Institutions of Higher Learning. International Education Studies, 7(2), 25-36. https://doi.org/10.5539/ies.v7n2p25

Bsharah, M., Gasaymeh, A. M., \& Abdelrahman, M. B. (2014). The Relationship between the Use of Social Networking Sites (SNS) and Perceived Level of Social Intelligence among Jordanian University Students: The Case of Facebook. International Journal of Psychological Studies, 6(3), 1. https://doi.org/10.5539/ijps.v6n3p1

Dougherty, K. (2015). Factors That Influence College Faculty to Adopt Digital Technologies in Their Practice. Higher Education in Transformation Conference, Dublin, Ireland, 2015, 307-318.

Fathema, N., Shannon, D., \& Ross, M. (2015). Expanding the Technology Acceptance Model (TAM) to examine Faculty use of Learning Management Systems (LMSs) in higher education institutions. MERLOT Journal of Online Learning and Teaching, 11(2), 210-232.

Fisher, J. (2003). How to Make an Incentives and Rewards System? Dar Al-Farouq for Publishing, Cairo, Egypt.

Gasaymeh, A. M. M. (2009). A study of faculty attitudes toward internet-based distance education: A survey of two Jordanian public universities (Doctoral dissertation, Ohio University).

Gasaymeh, A. M. M., \& Aldalalah, O. M. (2013). The Impact of Using SMS as Learning Support Tool on Students' Learning. International Education Studies, 6(10), 112-123. https://doi.org/10.5539/ies.v6n10p112

Gasaymeh, A. M. M., \& Qablan, B. M. (2013). SMS as Out-of-Class, Student-Instructor Interaction Tool: A Case Study of Jordanian Graduate Students' Perceptions and Usage. International Education Studies, 6(8), 147. https://doi.org/10.5539/ies.v6n8p147

Gasaymeh, A. M. M., Al-Tawel, A. M., Al-Moghrabi, K. G., \& Al-Ghonmein, A. M. (2017). University Students' Perceptions of the Use of Digital Technologies in their Formal Learning: A Developing Country Perspective. International Journal of Learning and Development, 7(3), 149-164. https://doi.org/10.5296/ijld.v7i3.11666

Gautreau, C. (2011). Motivational factors affecting the integration of a learning management system by faculty. Journal of Educators Online, 8(1). https://doi.org/10.9743/JEO.2011.1.2

Hamdan, R., \& Al-Saket, Y. (2011). Stimulation and Its Effect on the Organizational Loyalty of the Individuals and Workers in the Governmental Organizations. MA Thesis in Business Administration, An-Najah National University, Nablus, Palestine.

Hashem, T. (1975). Modern Trends in Management. Dar Al-Kitab Al-Jam'ie, Cairo.

Helal, M. (2009). Strategic Thought and Planning. Performance Development Center for Growth and Publishing, Cairo. 


\section{Macrothink}

International Journal of Education ISSN 1948-5476 2017, Vol. 9, No. 3

Margaryan, A., Littlejohn, A., \& Vojt, G. (2011). Are digital natives a myth or reality? University students' use of digital technologies. Computers \& education, 56(2), 429-440. https://doi.org/10.1016/j.compedu.2010.09.004

Prensky, M. (2001). Digital natives, digital immigrants: do they really think differently? On the Horizon, 9(6), 1-6. https://doi.org/10.1108/10748120110424843

Rabab'ah, A. (2003). Human Resources Management. Dar Safa'a for Publishing and Distribution. Amman.

Salehi, M., Abdolahi, M., Tabaghdehi, S. K. H., \& Mastari, F. (2014). Factors Affecting the Use of Information and Communication Technologies Faculty Members. Stud, 4(3), $702-711$.

Schulz, R., Isabwe, G. M., \& Reichert, F. (2015, September). Investigating teachers motivation to use ICT tools in higher education. In Internet Technologies and $\begin{array}{llll}\text { Applications (ITA), } & 2015 \quad \text { (pp. }\end{array}$ https://doi.org/10.1109/ITechA.2015.7317371

Zweilef, M. (2000). Individuals' Management (Through a Quantitative Perspective) and the Human Relations. Dar Majdalawy for Publishing, Amman.

\section{Copyright Disclaimer}

Copyright for this article is retained by the author(s), with first publication rights granted to the journal.

This is an open-access article distributed under the terms and conditions of the Creative Commons Attribution license (http://creativecommons.org/licenses/by/3.0/). 